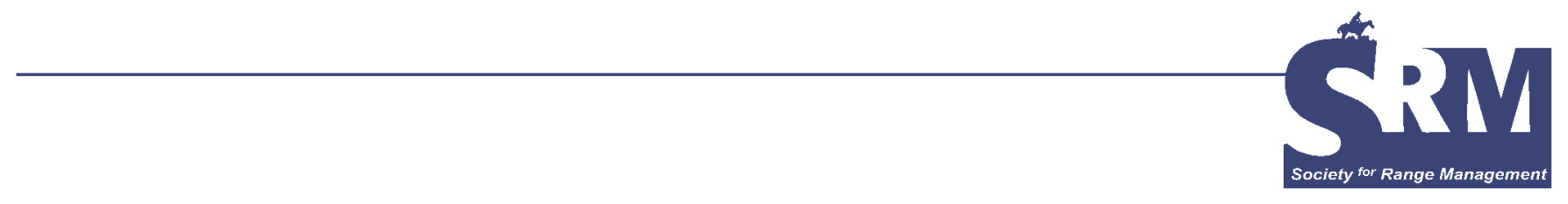

\title{
The Language of Rangeland Science
}

\section{By E. E. Grings}

Editor's Note: This paper was developed out of a talk at the Professional Issues Luncheon at the 2004 SRM meetings, where the topic was "Communicating Rangeland Ecology to a Diverse Audience." We should all take heed of the comments.

T was out in my garden recently when a troop of children neared the corner. A preschooler leading the pack on his tricycle called back to his mother, "Which way are we going, Mom? Do we go straight or turn?"

His mother responded with, "We're going forward."

The young boy sat on his tricycle for a few minutes before turning back to his mother and asking, "Which way is forward, Mom?”

The word "forward" was a simple concept to the 30something mother, but the term was not within the preschooler's experience. We forget how much we have learned over the years and that technical terms we use daily are unfamiliar to others. Our choice of words is of critical importance when trying to explain scientific concepts, such as the basic ecology associated with grazing management. If we want the public to listen to our management concerns, we need to help them understand and to be interested. We will lose our audience if they do not understand our terminology. We use technical jargon, uncommon words, or even regionalisms that not everyone understands. Phrases like "belowground biomass" may not be needed if the word "roots" conveys the same idea. I know I have been stopped by my urbandwelling family and friends more than once to clarify terms such as "open heifer" or "running a transect."

This article has been peer reviewed.
In addition to the need to define specific terms, we need to be aware that words can have different meanings. Familiar words can be unclear when used in an unfamiliar context. Although someone would understand if you said you had spent the afternoon browsing in a bookstore, they might not relate the term browsing to a feeding pattern in goats. The word "range" carries 16 definitions in my American Heritage Dictionary. The definition indicating that range is "a testing area in which rockets and missiles are fired and flown" falls just before "an extensive area of open land on which livestock wander and graze."

Do not let an audience go astray by giving them the opportunity to think of a different definition than you intend. I sat in a meeting with a group of livestock producers not too long ago where the term "landscape ecology" was being used. A man in the audience raised an objection to the term because he was defining "landscape" as the verb meaning "to redesign" or "to make more attractive." He was uncomfortable with the idea of redesigning our rangelands.

Awareness of the origins of terminology helps us recognize the potential for misunderstanding. We commonly use synonyms or metaphors to clarify biological processes. We discuss "food webs" and "state and transition models." These terms are used to help us visualize some very complex processes.

Although some guides to science communication encourage the use of metaphor, others have cautioned that some metaphors may be inappropriate. In a 2003 issue of Science, ${ }^{1}$ several researchers penned an essay called "Natural Enemies-Metaphor or Misconception?" in which they cautioned that metaphors may not always convey the intended message. An example was the term "natural enemy." In using this phrase, we may be referring to a predator-prey relationship that occurs in nature, but by use of 
the term "enemy," have we asked our reader whether right and wrong are involved?

As I read this Science essay I thought of other examples of metaphors that could create confusion. One is the word "disturbance." We refer to fire and grazing as "disturbances." Are we setting ourselves up for negative views of fire and grazing on rangelands because our audience thinks of the definition of disturb as "to break the rest, quiet or calm" rather than "to cause to move from a settled position"?

Communicating the science involved in rangeland management to diverse audiences is important for successful adoption of land management practices, for effective decision-making by land management agencies and lawmakers, and for general public awareness. To effectively communicate information about the resource, it is important that we find a way to relate to our audience's world and understand that we don't all share the same vocabulary.

Author is Range Animal Nutritionist, US Department of Agriculture-Agricultural Research Service, Fort Keogh Livestock and Range Research Laboratory, Miles City, MT 59301, Elaine@larrl.ars.usda.gov.

\section{Reference}

1. Chew, M. K., and M. D. Laubichler. 2003. Natural enemies - metaphor or misconception? Science 301(5629):52-53.

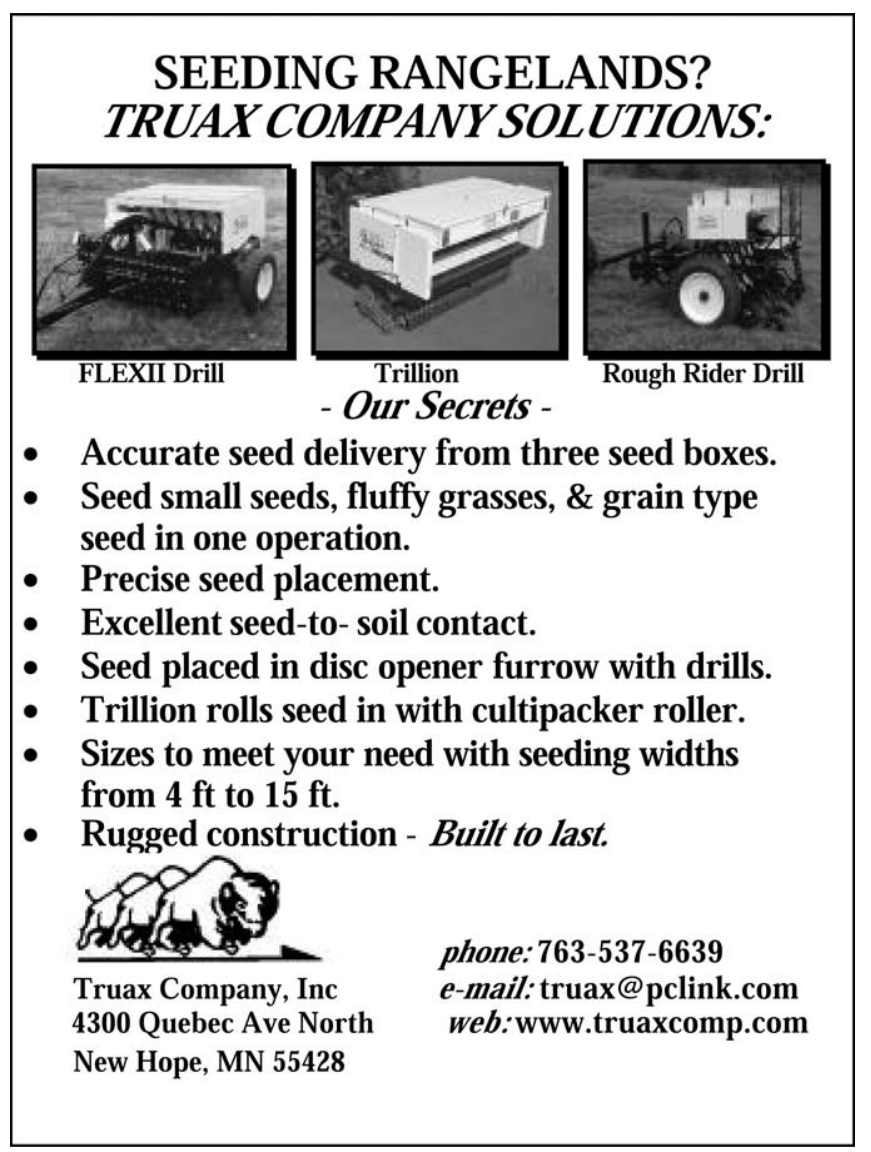

